\title{
BMJ Open Translational deep phenotyping of deaths related to the COVID-19 pandemic: protocol for a prospective observational autopsy study
}

\author{
Mikkel Jon Henningsen (D) , ${ }^{1}$ Apameh Khatam-Lashgari, ${ }^{1}$ Kristine Boisen Olsen, ${ }^{1}$ \\ Christina Jacobsen, ${ }^{1}$ Christian Beltoft Brøchner (1) , ${ }^{2}$ Jytte Banner ${ }^{1}$
}

To cite: Henningsen MJ, Khatam-Lashgari A, Olsen KB, et al. Translational deep phenotyping of deaths related to the COVID-19 pandemic: protocol for a prospective observational autopsy study. BMJ Open 2021;11:e049083. doi:10.1136/ bmjopen-2021-049083

- Prepublication history and additional supplemental material for this paper are available online. To view these files, please visit the journal online. (http://dx.doi.org/10.1136/ bmjopen-2021-049083).

Received 20 January 2021 Accepted 28 July 2021

Check for updates

(c) Author(s) (or their employer(s)) 2021. Re-use permitted under CC BY-NC. No commercial re-use. See rights and permissions. Published by BMJ.

${ }^{1}$ Section of Forensic Pathology, Department of Forensic Medicine, University of Copenhagen Faculty of Health and Medical Sciences, Copenhagen, Denmark

${ }^{2}$ Department of Pathology, Rigshospitalet, Copenhagen, Denmark

Correspondence to Professor Jytte Banner; jytte.banner@sund.ku.dk

\section{ABSTRACT}

Introduction The COVID-19 pandemic is an international emergency with an extreme socioeconomic impact and a high mortality and disease burden. The COVID-19 outbreak is neither fully understood nor fully pictured. Autopsy studies can help understand the pathogenesis of COVID-19 and has already resulted in better treatment of patients. Structured and systematic autopsy of COVID-19-related deaths will enhance the mapping of pathophysiological pathways, not possible in the living. Furthermore, it provides an opportunity to envision factors translationally for the purpose of disease prevention in this and future pandemics. This is the protocol for an autopsy study that offers an umbrella for deep and diverse investigations of COVID-19-related deaths, including a systematic investigation of 'long' COVID-19 by means of extensive and systematic tissue sampling.

Methods and analysis A COVID-19-specific autopsy algorithm has been created to cover all cases undergoing clinical or forensic autopsy in Denmark. The algorithm describes advanced tissue sampling and a translational analytical follow-up for deep phenotyping. The translational approach covers registry data, postmortem imaging, gross autopsy findings, microscopic organ changes, postmortem toxicology, postmortem biochemical investigation, microbiological profiling and immunological status at the time of death, and future research projects covering genetics and epigenetics on an organ level.

Ethics and dissemination This study has been approved by the Regional Ethics Committee of the Region of Greater Copenhagen (No: H-20078436) and the Danish Data Protection Agency (No: 2002-54-1080). Next of kin gave informed consent to research. The study results will be published in peer-reviewed journals.

Trial registration number This study is purely observational and, as such, does not meet the criteria of the International Committee of Medical Journal Editors for clinical trials; thus, there is no need for registration in a database of research trials, such as clinical trials. To facilitate cooperation in research, provide transparency on case recruitment for publications to come and to avoid unnecessary duplicate work, we nevertheless wish to publish our protocol.

\section{INTRODUCTION}

In late 2019 in Wuhan, China, an outbreak of pneumonia caused by SARS-CoV-2 emerged, ${ }^{1}$
Strengths and limitations of this study

- A standardised, prospective autopsy study on COVID19-related deaths with systematic data collection.

- A multidisciplinary, translational approach elucidating changes from protein level to whole human.

- A comprehensive biobank and extensive registry data as an umbrella for planned and future research.

- The internal control group partly compensates for the observational design.

- Limited by a selected sample of COVID-19 diseased only including the ones undergoing autopsy.

and later evolved into the global COVID-19 pandemic that has claimed millions of lives. Along with SARS-CoV ${ }^{2}$ and Middle East respiratory syndrome coronavirus (MERS-CoV), ${ }^{3}$ it is the third coronavirus that causes severe symptoms in humans. Coronaviruses mutate frequently, and many variants of SARS-CoV-2, each with its own characteristics, have already been registered. ${ }^{45}$

Historically, autopsy studies have provided novel insights on epidemic disease. ${ }^{6}$ Important knowledge of the pathophysiology of coronavirus was gained both from autopsy studies during the $\mathrm{SARS}^{7}$ and MERS epidemics ${ }^{8}$ and currently from autopsy studies on COVID-19related deaths. ${ }^{9-12}$ The importance of autopsy studies in the current pandemic is already reflected in better treatment of patients, for example, adjusting anticoagulative therapy for COVID-19. ${ }^{10}$ Besides a few cases in some autopsy studies on COVID-19, ${ }^{13-16}$ only two case series $^{17} 18$ and a study by Romanova et $a l^{19}$ include out-of-hospital deaths. Autopsies of hospital deaths demonstrate hospitalised fatal cases and late disease stages influenced by treatment and forensic autopsies provide an overview of different stages of disease.

Much is known about the pathophysiology of SARS-CoV-2 but unanswered questions still 
remain. SARS-CoV-2 binds via its spike protein to ACE2 receptors located on different cell types, including type II alveolar cells, respiratory epithelial cells, ${ }^{5} 72021$ myocardial cells, ${ }^{22}$ cells in the oesophagus and ileum, cells in the kidneys and bladder, and endothelial cells, ${ }^{23}$ which may explain the extrapulmonic symptoms observed in patients suffering from COVID-19. ${ }^{24}$ The transmembrane protease serine 2 (TMPRSS2) is also suspected to play a vital role.

It is well known that old age, and comorbidities such as cardiovascular disease (CVD), diabetes, chronic lung disease, chronic kidney disease, cancer and obesity increase the disease burden, ${ }^{125-33}$ and severe COVID-19 includes sepsis, acute respiratory distress syndrome (ARDS), acute cardiac and kidney injury, arrhythmia, as well as secondary infection and, ultimately, death. ${ }^{12734}$ The importance of CVD as a risk factor for increased morbidity and mortality during COVID-19 has become progressively apparent, ${ }^{29} 3132$ but the exact pathogenesis is not fully understood. In the 2003 Toronto SARS outbreak, SARS-CoV viral RNA was detected in $35 \%$ of the autopsied hearts, and in these patients, the infection was associated with a more aggressive course of illness. ${ }^{22}$ Myocardial injury was evident from rising levels of cardiac troponin I in those who did not survive, ${ }^{34}$ and in the current pandemic, inflammation and microthrombi have been detected in the coronary arteries. ${ }^{35}$ ARDS is well known from the SARS and MERS epidemics, ${ }^{36} 37$ and the ongoing COVID-19 pandemic. The involvement of other organs and the severity of COVID-19 are still not fully understood and secondary effects mediated by a modification of the immunological reaction are assumed to contribute to the severity of COVID-19. ${ }^{13638-40}$

An emerging problem is so-called 'long' COVID-19, or postacute COVID-19, which is defined as persisting symptoms and/or long-term complications, including neurological symptoms with disturbed senses, more than 4 weeks after symptom debut. ${ }^{41}$ Retrospective studies on initial COVID-19 survivors have demonstrated excess death and disease burden up to several months after hospital discharge. ${ }^{42}{ }^{43}$ In England, Ayoubkhani et al found that in the months after discharge a great number of patients (47 780 people) who had been hospitalised with COVID-19 died at an eight times greater rate than matched controls. In an American setting, Al-Aly et al found that patients who had suffered from COVID-19 experienced increased burden of respiratory, neurological, mental, metabolic, cardiovascular, musculoskeletal and gastrointestinal diseases, an increased use of nonopioid analgesics, opioids, antidepressants, anxiolytics and benzodiazepines and had increased risk of death.

Examination of the brain has been avoided for safety reasons in many autopsy studies on COVID-19, ${ }^{44-51}$ which leaves a knowledge gap regarding central nervous system (CNS) involvement. Though a large number of autopsy studies have been published on COVID-19, a large proportion is on less than three deceased ${ }^{1744} 452-62$ and some are restricted to leaving organs 'in-situ' for gross examination and tissue sampling, ${ }^{44} 53$ or rely on biopsies only. ${ }^{38}$ 63-77 Studies with complete autopsies of 3-100 deceased have been performed, ${ }^{9-12} 47-5078-90$ but also some of these were restricted to 'in situ' organ examination. ${ }^{9}{ }^{50}$

Internationally, SARS-CoV-2 is classified into Hazard Group 3 and due to fear of transmission from the deceased to autopsy personnel, several guidelines on COVID-19 autopsies were published in the early stages of the pandemic by, for example, Hanley et al and Santurro et al..$^{91}{ }^{92}$ In Denmark, SARS-CoV-2 is classified into Hazard Group 2. ${ }^{91}$ In this respect, the handling of those who die of a possible SARS-CoV-2 infection with or without COVID-19 is possible following the standard procedures at Danish autopsy facilities, including postmortem imaging, and furthermore allows for a comprehensive autopsy study. ${ }^{1093}$

Postmortem imaging has emerged as a promising tool for performing non-invasive 'autopsy', ${ }^{94}$ and may be of value in biohazardous cases. Only a few autopsy studies have included postmortem imaging. ${ }^{95}$

\section{Rationale for study}

Autopsy studies enable extensive and unique examination and tissue sampling, which is not possible in living patients. No autopsy studies with extensive tissue sampling were initiated during neither the SARS-CoV nor the MERS-CoV epidemic, ${ }^{6}$ and only a few studies in the current SARS-CoV-2 pandemic include more than 25 deceased. ${ }^{10-12} 48517781$ To our knowledge, no autopsy study on 'long' COVID-19 has been performed.

This paper describes the protocol for an ongoing multicentre autopsy study of COVID-19-related deaths, and presents some of the planned and future research projects. The COVID-19 autopsies constitute a framework of complete, systematic autopsy, with multimodal postmortem imaging, extensive predefined tissue sampling, including biobanking at $-80^{\circ} \mathrm{C}$, and toxicological, microbiological and molecular analyses combined with genetic examination. Furthermore, the extensive Danish registries of disease, medication and socioeconomic status allow for consideration of factors beyond those present at autopsy, which provides the opportunity for deep and diverse investigations of COVID-19-related deaths and a systematic investigation of 'long' COVID-19 by means of autopsy.

We hypothesise that combining registry data with immediate autopsy findings, advanced molecular, pharmaceutical, immunological, microbiological, genetic and epigenetic investigations in those who die of COVID-19 or suffer from 'long' COVID-19 will help understand the pathogenesis of COVID-19, which is the rationale for conducting the here described study.

\section{Aims and objective}

The overall aim is to reduce death and disease burden in COVID-19 and future pandemics. The overall objective to reach this aim is to identify high-risk profiles for 
COVID-19-related deaths. Several research projects are already defined and have the following aims:

\section{Project 1}

Postmortem imaging aims to register imaging findings in COVID-19-related deaths and correlate them to autopsy findings and antemortem imaging.

\section{Project 2}

Macroscopic and microscopic changes aim to contribute to basic understanding of pathological and histopathological pre-existing and COVID-19-related changes in all organs, and will constitute a basis for comparison to imaging findings and furthermore relate to advanced molecular investigations.

\section{Project 3}

Chemical and toxicological analysis aims to both identify potential harmful or beneficial drugs and medications present in COVID-19-related deaths, and to determine to what extent medication is distributed to reach the lung tissue. Furthermore, it aims to phenotype risk profiles.

\section{Project 4}

Loss of smell aims to identify how the smell epithelium, the olfactory nerve, the olfactory nerve bulb and the taste buds are affected by the invasion of the virus, and to determine whether ACE2 receptors and the TMPRSS2 are present in the olfactory pathway or in supporting cells.

\section{Project 5}

Advanced microbiological examination aims to improve the understanding of infection, detect mutation rate of SARS-CoV-2, validate the immunochemical assays for detection of SARS-CoV-2 antibodies for use on autopsy samples and examine ACE2 receptor expression, the significance of the morphology of the paranasal sinuses and whether this correlates to the microbiome.

\section{Project 6}

Aberrant signalling aims to establish the effects of SARS-CoV-2 on specific organs, for example, the liver, and to elucidate the role of aberrant ACE2/angiotensin II signalling.

\section{Research question}

This observational study collects tissue and data for a biobank aiming at answering what happens at gene, protein, cell, tissue and organ level in the individual human infected with SARS-CoV-2. More specifically, immediate autopsy findings combined with deep and advanced molecular investigation will aim at answering the following research questions: (1) Which comorbidities, autopsy findings and antemortem diagnosis are present in COVID-19-related deaths? (2) What is the cause of death? (3) How does postmortem imaging correspond to autopsy findings? (4) What pharmaceuticals are present in COVID-19-related deaths, and how does their presence correspond to organ changes? (5) What is the impact of immunological mechanisms? (6) What are the virological, bacteriological and immune status of the deceased in relation to COVID-19? (7) Who is at risk of death from COVID-19? (8) What is the underlying role of genetics and epigenetics? (9) When is death caused by COVID-19, accelerated by COVID-19 or unrelated to SARS-CoV-2 infection?

The first two research questions, covered by subprojects 2 and 4, have already been investigated by others. The repetition in this study serves to correlate the findings using the herein proposed advanced methods in each deceased individual.

\section{Time frame}

Inclusion began on 1 May 2020. As of December 2020, forty cases had been included, and 80 by May 2021. The inclusion will continue as long as the epidemic exists in Denmark, and an additional 6 months to capture 'long' COVID-19 cases. A decrease in cases is expected from mid-2021. Tentative analysis will be initiated in mid-2021. The first 40 cases were all included on the basis of confirmed or suspected acute COVID-19.

\section{METHODS AND ANALYSIS \\ Study setting}

This is a prospective, autopsy-based, observational cohort study based at the Section of Forensic Pathology, Department of Forensic Medicine, University of Copenhagen, Denmark. The study is being conducted in collaboration with the Department of Pathology at Rigshospitalet, Copenhagen.

Cases may be included from the other two forensic institutes in Denmark and from pathology departments in eastern Denmark. All forensic institutes and the Department of Pathology at Rigshospitalet employ the same COVID-19-specific autopsy algorithm. Cases are recruited either from deceased hospitalised patients or at the medicolegal inquest.

\section{Additional data}

Additional registry data will be acquired from national health registries, including, but not limited to, the Register of Medicinal Product Statistics (Lægemiddelstatistikregisteret), which contains data on all sales of prescription medicine and over-the-counter medicine reported from Danish pharmacies ${ }^{96}$; the National Patient Register (Landspatientregisteret), which contains data on utilisation of secondary healthcare and includes admissions, ambulatory visits and visits to emergency rooms $^{97}$; the National Health Insurance Service Register (Sygesikringsregisteret), which concerns utilisation of primary healthcare including dentists, chiropractors, physiotherapists, psychologists and podiatrists; the Attainment Register, ${ }^{98}$ which gives insight into the highest education attained for each person and is updated once a year; and the Danish registers on personal labour market 
affiliation from Statistics Denmark, which contains employment status on each Danish citizen, which is also updated every year.

\section{Imaging and autopsy}

Postmortem CT (PMCT) is performed in accordance with internal procedures on all cases handled at the forensic departments in Denmark. The institutes are accredited by the Danish Accreditation and Metrology Fund and ISO/ IEC17020:2012. The Department of Forensic Medicine, University of Copenhagen, may also perform postmortem MRI (PMMRI) of the brain and heart in cases suspected of COVID-19. PMMRI is superior to PMCT for soft tissue visualisation, especially of the $\mathrm{CNS}^{99}$ and the heart. ${ }^{100}$ PMMRI is routinely used at the University of Copenhagen in cases with suspected CNS or cardiac disease as it allows in situ diagnosis. It is too time consuming to employ on all regular cases.

Autopsy is performed according to international standards, ${ }^{101}{ }^{102}$ with an additional COVID-19-specific algorithm specifying extensive tissue sampling. Boardcertified clinical pathologists perform histopathological analysis.

\section{Documentation}

Standardised and pro-necessaire photodocumentation and standardised written report forms are used for both gross and radiological findings.

\section{Sampling}

The COVID-19-specific algorithm dictates tissue sampling, location, sidedness and so on. Fluids for chemical and toxicological analysis are collected in tubes both with (urine and intravitreous liquid) and without (peripheral blood, urine, intravitreous liquid, gall, stomach contents and heart blood) additives, and solids for chemical and toxicological analysis include muscle, liver, brain and hair. For a complete overview of the sampled tissue, see online supplemental appendix 1. Additional tissue may be sampled on a case-to-case basis (eg, on discovery of a tumour).

\section{Analysis}

It is standard procedure to sample and store tissue at autopsy, as it is not possible to acquire these at a later point. The tissue samples are stored to enable cost-effective ad hoc analysis and later reanalysis, should police investigation or clinical questions prompt such. An extended autopsy algorithm has been developed for handling of all cases with suspected or confirmed current or prior (death within 6 months of symptoms) COVID-19. This algorithm serves diagnostic and work safety purposes, but also serves a research purpose. All autopsies are requested by either police or clinical hospital departments.

The comprehensive tissue sampling in this protocol is for research purposes and is analysed in several research projects, as briefly detailed here.
Project 1

Postmortem imaging. Postmortem images, PMCT and PMMRI, will be interpreted de novo by researchers blinded to autopsy findings and reported in structured forms. Quantitative tools for scoring organ changes in postmortem imaging will be developed and the imaging findings will be correlated to autopsy and histopathological findings.

\section{Project 2}

Macroscopic and microscopic changes. Standard histopathological analyses of tissue samples will be performed by conventional bright field light microscopy of standard H\&E stained slides supported by various special stains (eg, periodic acid-Schiff (PAS), PAS with diastase, Alcian blue-van Gieson) and immunohistochemical markers (eg, inflammatory markers anti-CD3, anti-CD20, antiCD68; complement deposits such as anti-C4d). The examinations will be supported by other special stains and specific antibodies, immunofluorescence analysis of expression patterns and molecular analysis including PCR analysis, in situ hybridisation and potentially multiplex immunofluorescence and NanoString GeoMx Deep Spatial Profiling of regions of interest. A uniform way of describing changes will be carried out across organs and related to gross findings and patient data undertaken by a specialist in clinical pathology and molecular pathology. A non-exhaustive list includes morphological changes, detection of virus and virus-related changes, inflammation, vascular changes including thrombosis and development of microthrombi and fibrotic changes.

\section{Project 3}

Chemical and toxicological analysis. The chemical and toxicological examinations will be performed by the Section of Forensic Chemistry, Department of Forensic Medicine, University of Copenhagen, with established methods such as time-of-flight mass spectrometry, liquid chromatography and specific liquid chromatography tandem mass spectrometry. Sample analysis will include lung tissue, blood and serous fluids. Risk profiles will be determined through metabolomic analysis and clinical biochemical investigation of C-reactive protein, cortisol and biomarkers of, for example, diabetes and hormones.

\section{Project 4}

Loss of smell. The well-known long-term effects of COVID-19 on the sense of smell will be investigated by histopathological analysis as detailed for subproject 2 to determine the expression of ACE2 receptors and the TMPRSS2 and supported by PCR analysis to identify the potential presence of SARS-CoV-2 in the tissue.

\section{Project 5}

Advanced microbiological examination. The Department of Microbiology and Infection Control, Statens Serum Institut (SSI), will perform virological analysis with three commercially available serological tests which will be evaluated for their sensitivity and specificity to detect 
SARS-CoV-2. To detect the presence of SARS-CoV-2 in tissues, specific PCR will be performed followed by wholegenome sequencing of virus for SARS-CoV-2-positive isolates, microbiome analysis and multiplex RT-PCR-based assay for 17 different respiratory tract viruses. Bacteria will be detected on growth media as in routine practice. Levels of antibodies in relevant fluids will be assessed.

\section{Project 6}

Aberrant signalling. The effects of SARS-CoV-2 and aberrant ACE2/angiotensin II signalling in specific organs, for example, the liver, will be explored with targeted transcriptomic analysis (RNAseq), metabolomic analyses and fluorescence in situ hybridisation to investigate the immune cell and metabolomic landscapes of SARS-CoV-2 infection, and also to investigate the mechanism of reninangiotensin system and ACE2/angiotensin II-induced liver damage. Furthermore, the SARS-CoV-2-induced changes to the transcriptome will be examined.

\section{Data storage}

All electronic data, files and images, are stored on a local closed network without connection to the internet. The project data are stored in a database and processed on the same local closed network. Data are managed with software also used for routine work. All cases are assigned a unique project identification number

\section{Statistical analysis}

This is an umbrella study for several ongoing research projects. The biobank will enable future projects to use the data sampled. The statistical programmes, methods and sample sizes will vary between projects and will be described in detail in publications to come. In brief, descriptive statistics will be used to quantify typical findings in COVID-19-related deaths, divided into relevant groups of, for example, in-hospital death, with intensive care unit (ICU) stay, acute COVID-19, 'long' COVID-19, etc, and differences between groups will be analysed with McNemar's test, $\chi^{2}$ test and Student's t-test. For continuous covariates, regression models will be employed. P values $<0.05$ are considered significant. Analysis will be restricted to cases with complete data for the given subproject. As missing data most likely will be a result of investigator error rather than reasons within the deceased subject, we assume a minimal bias from this practice, although it may reduce the effective sample size.

For evaluating the effects of pharmaceuticals and drugs, we will perform multivariate analysis adjusted for sex, age and known diseases, and comparison made to findings in matched non-COVID-19-related deaths to elucidate the role of medications in COVID-19-related deaths.

For evaluating the congruence between imaging and autopsy as well as histopathological findings, we will calculate the sensitivity and specificity for PMCT and MRI, and to assess intraobserver and interobserver agreement we will calculate the Cohen's kappa.

\section{Cohort description}

In this study, the deceased are included in two ways. In Denmark, all deaths are reported to the police when a criminal act, suicide or accident caused death, when a person is found dead, when death was sudden and not medically expected, when work-related disease is suspected to have caused death, when death may have been a result of error in medical treatment or disease prevention, when a person dies in custody and when it cannot be ruled out that the police may have an interest in the death.

At medicolegal inquest, the police are advised by either a medical health officer or a forensic pathologist, in accordance with the Danish Health Act, and decide whether or not a forensic autopsy is required. By law, the police always request a forensic autopsy when a criminal offence may have contributed to death (or later suspicion of such may arise), when manner of death cannot be determined at medicolegal inquest and police affairs deem autopsy necessary, and when illicit drugs are suspected to have caused death.

Inclusion criteria for the research project and biobank are at least one of the following: confirmed or probable history of current or prior COVID-19, positive antemortem test or PMCT findings indicative of COVID-19 (eg, ground-glass opacities, crazy paving, consolidation, arcade sign and traction bronchiectasis). Negative antemortem testing does not result in exclusion, as neither sensitivity nor specificity of this test is perfect.

The Department of Forensic Medicine, University of Copenhagen, and the Department of Pathology, Rigshospitalet, Copenhagen, include all cases that meet the stated criteria. Additional cases from eastern Denmark may be referred from other departments of clinical pathology to Rigshospitalet for autopsy. All forensic departments in Denmark employ the described COVID-19 autopsy algorithm, and this study therefore potentially covers all of Denmark. Clinical departments (eg, lung medicine, infectious diseases and ICUs) may request an autopsy from the departments of pathology that apply the same inclusion criteria as that for police-requested cases, except there is no inclusion based on PMCT findings. PMCT is then performed, if included.

Included cases in which neither a confirmed history of COVID-19 nor SARS-CoV-2 demonstrated on postmortem virological examination by SSI will serve as internal controls. Figure 1 illustrates the inclusion flow chart.

Prior COVID-19 is defined as death within 6 months of first symptoms, as the studies by Ayoubkhani $e t$ al and Al-Aly et al on initial COVID-19 survivors demonstrate excess death and disease burden up to several months after hospital discharge. ${ }^{42} 43$

Cases with extensive putrefaction, too large for PMCT, where consent cannot be obtained and where the COVID19-specific autopsy algorithm is incompatible with the purpose of the autopsy (eg, homicide investigation), are excluded. In forensic pathology, the deceased may be discovered at any given time after death. The interval 

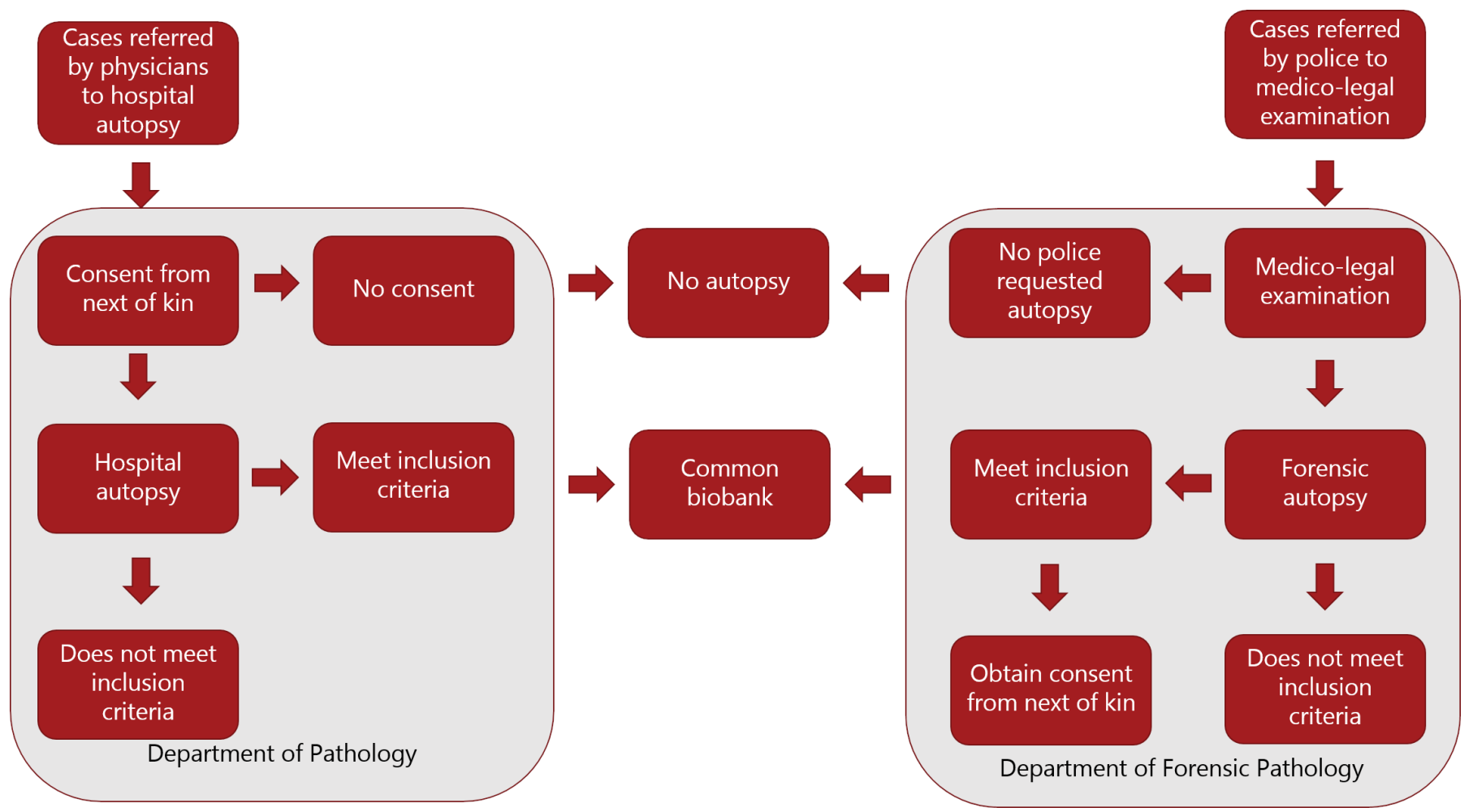

Figure 1 Inclusion and consent flow chart.

between death and autopsy is potentially unknown. For hospital deaths, the deceased is moved to the morgue after the doctor confirms the presence of rigour mortis or livor mortis, though practical circumstances may delay this process.

In order to determine the 'extensive putrefaction' objectively and reproducibly, we defined this as a radiological alteration index (RAI) of $>50$ (scale from 0 to 100) and applied analysis as described by Egger et al. ${ }^{103}$ The RAI is a semiquantitative estimation of the extent of postmortem gas formation in seven anatomical locations as graded from 1 to 3 on PMCT, and has been demonstrated to correlate well with the grade of external putrefaction. ${ }^{104}$

\section{Patient and public involvement}

Neither patients nor next of kin were involved in the design of this study.

\section{ETHICS AND DISSEMINATION}

In Denmark, research on the deceased requires informed consent from next of kin. For autopsies requested by clinical departments, consent to research and autopsy is given simultaneously. For police-requested forensic autopsies, police either obtain consent to autopsy from next of kin or obtain a court order mandating autopsy. For research purposes on forensic autopsies, next of kin are contacted through letter at the earliest 1 month after autopsy, and if there is no response, then by telephone. The same approach has been successfully used in a previous national study, the SURVIVE study (SURVIVE: let the dead help the living - an autopsy-based cohort study for mapping risk markers of death among those with severe mental illnesses), ${ }^{105}$ and it is believed to be the least emotionally disturbing to next of kin. The obtained consent rate in the SURVIVE study was more than $90 \%$ of the included cases. ${ }^{105}$ The current study has been approved by the Regional Ethics Committee of the Region of Greater Copenhagen (No: H-20078436) and the Danish Data Protection Agency (No: 2002-54-1080).

All data are available on request to the steering group on the condition that the intended research is sound and that legal matters, such as General Data Protection Regulation, are addressed properly. Results will be published in peer-reviewed journals.

\section{DISCUSSION}

COVID-19 is an ongoing global crisis, and has already sparked many autopsy research projects. Summaries of these studies are provided in systematic reviews by Maiese et al, Satturwar et al, Peiris et al and Borczuk. ${ }^{95} 106-108$ The tissue sampling and auxiliary investigations performed have been extensive, but also limited by restrictions on how to perform a safe autopsy in suspected COVID-19related deaths. Given a novel and deadly disease, it was necessary to report the findings as soon as possible. This results in many smaller studies with either a few selected investigations or selected reporting.

In autopsy studies, all relevant tissues must be sampled and stored to answer current and future research questions. Matschke et al had 110 potentially eligible cases, but only sufficient samples from 43 cases to perform their 
study on the brain in COVID-19. ${ }^{109}$ This highlights why prospective, systematic sampling is necessary to provide a broader understanding of the pathogenesis of COVID-19.

Most autopsy studies have been performed on hospitalised patients, but a few studies ${ }^{13-16} 19$ and case series ${ }^{1718}$ include out-of-hospital deaths. The current study will recruit both clinical and forensic cases of individuals deceased up to 6 months after COVID-19 symptoms. Our cases therefore include both hospitalisations with and without ICU and out-of-hospital deaths, and therefore reflect a heterogeneous population both in terms of age, sex, overall health and circumstances of life and death. Patients recruited from hospitals will most likely differ from those not hospitalised and, likewise, those recruited specifically from ICUs will most likely differ from other patients. Cases recruited from hospitals will likely have died from COVID-19. Police-requested autopsies will provide examples of COVID-19-related deaths or pathological changes in individuals who did not manage to seek help, had a quicker course of disease or died from other causes. Collectively, the heterogeneity of the study population provides an opportunity to document COVID-19 at all stages of disease, and thus give a fuller picture, as well as an opportunity to provide details on the longterm health consequences, including 'long' COVID-19. Conversely, statistical inference is more difficult as each group may be small. This issue will be handled based on results of statistical analysis.

A major issue in the SARS-CoV-2 pandemic is to determine the cause of death from current SARS-CoV-2 infection against death from the consequences of SARS-CoV-2 infection against death from other causes while infected with SARS-CoV-2. Edler et al proposed categorising deaths as (1) definite COVID-19-related deaths, (2) probable COVID-19-related deaths, (3) possible COVID-19-related deaths, or (4) SARS-CoV-2 detected but unrelated to the cause of death. ${ }^{10}$ This categorisation is used in many industrialised countries and may prove relevant to investigate preventive measures, abandon unnecessary measures, steer pharmaceutical treatment and guide society in both this and future pandemics. To facilitate the comparison between our study and other studies, this categorisation will also be adopted in this study.

To our knowledge, no autopsy studies have investigated 'long' COVID-19, as they naturally have recruited cases of individuals deceased from acute COVID-19. As death and disease are increased in the months after initial infection, we also include cases that die within 6 months of first COVID-19 symptoms. Some 'long' COVID-19 symptoms are related to the CNS. Matschke et al have performed a neuropathological study on acute COVID-19-related deaths, ${ }^{109}$ but the CNS remains less well examined than other organs, such as the lungs. ${ }^{95}$ Our COVID-19-specific autopsy algorithm includes extensive sampling of brain tissue and neuropathological special investigation, and we hope our study will contribute to this area of research.

In all fields of medicine, multicentre studies carry the benefits of larger samples, faster recruiting, more generalisable results and smaller bias in sampling, but they require strict adhesion to protocol to avoid unsought heterogeneity. These benefits are reflected by an exponential growth in multicentre studies published on PubMed during the last 20 years. The current study, along with those by, for example, Carsana et al, Sonzogni et al, Borczuk et al and Basso $e t a l$, is an example of multicentre autopsy studies ${ }^{12} 354876$ that benefit from interdisciplinary cooperation in that, for example, forensic pathologists, clinical pathologists, neuropathologists, epidemiologists, virologists, otolaryngologists and chemists all contribute within their field of expertise to provide a translational understanding of COVID-19 from gene via organ to the deceased to benefit the living.

PMCT has been sparsely investigated. Of the first 28 autopsy studies published, only four included PMCT. ${ }^{95}$ In the living, CT serves as a diagnostic tool in COVID-19, ${ }^{110} 111$ but postmortem imaging is different from clinical radiology, ${ }^{112}$ and more research on the congruence between postmortem imaging findings and autopsy is needed.

Like all observational studies, this study is subject to selection bias, confounding and measurement errors. Cases suspected to be infected with SARS-CoV-2 may prove not to be. This makes the actual sample in this study smaller, but its strength is that these cases may serve as internal controls. Measurement error and misclassification are always a possibility, as is confounding. Information from police and hospital records may contain information vulnerable to recall, interviewer and confirmation bias.

In both forensic and clinical pathology in Denmark, two pathologists always inspect the organs and cosign the work in accordance with the standard procedures. It is expected that this standard practice would lessen the amount of measurement error and misclassification in the current study. Further, the timing of investigation and sampling should have a little effect, as all the deceased are kept in a morgue from death to autopsy.

Confounding will be handled through statistical analysis.

The here described study and biobank may seem superfluous given that the current COVID-19 pandemic seems to be lessening during spring 2021, with vaccine coverage improving by the hour. But this is only true for some parts of the world and the risk of future pandemics and epidemics with variants of SARS-CoV-2 remains. Growing populations living closely, humans living close to animals, extensive national and international travelling and climate change are all factors that will likely lead to future pandemics. ${ }^{13}$ Both MERS and SARS were coronaviruses, and bats harbour more than 91 variants of coronaviruses. ${ }^{113}$ This study and the biobank offer an opportunity to understand the pathogenesis of COVID-19-and the knowledge gained will help combat COVID-19 in, for example, South America, Africa and Asia, and hopefully future pandemics and epidemics with variants of coronavirus, as knowledge gained in one pandemic may help combat the next. ${ }^{6}$ There is no reason not to learn as much as possible about SARS-CoV-2 and 
COVID-19-related deaths in order to potentially improve diagnosis and treatment in future viral pandemics.

Acknowledgements Professor Niels Lynnerup should be acknowledged for his role in conceiving the study and securing external funding. Niels Walentin should be acknowledged for his contribution on electronic data handling and storage.

Contributors JB and CJ conceived the study and secured external funding through grants. JB is the chief investigator and guarantor. JB and KBO coordinated with the involved parties. JB, MJH and AK-L secured approval from the Ethics Committee for the research projects and the Data Protection Agency for the biobank. JB, CJ, KBO, MJH, AK-L and CBB contributed to the formation of the protocol. MJH and AK-L wrote the first draft. All authors contributed to the writing of the manuscript and approved the final version. MJH and AK-L consider this a shared first authorship.

Funding This study was supported by the Lundbeck Foundation with DKK2.5 million (approx $£ 300000$ ) (grant: R319-2020-896). Funds are managed by the University of Copenhagen.

Competing interests None declared.

Patient consent for publication Not required

Provenance and peer review Not commissioned; externally peer reviewed.

Supplemental material This content has been supplied by the author(s). It has not been vetted by BMJ Publishing Group Limited (BMJ) and may not have been peer-reviewed. Any opinions or recommendations discussed are solely those of the author(s) and are not endorsed by BMJ. BMJ disclaims all liability and responsibility arising from any reliance placed on the content. Where the content includes any translated material, BMJ does not warrant the accuracy and reliability of the translations (including but not limited to local regulations, clinical guidelines, terminology, drug names and drug dosages), and is not responsible for any error and/or omissions arising from translation and adaptation or otherwise.

Open access This is an open access article distributed in accordance with the Creative Commons Attribution Non Commercial (CC BY-NC 4.0) license, which permits others to distribute, remix, adapt, build upon this work non-commercially, and license their derivative works on different terms, provided the original work is properly cited, appropriate credit is given, any changes made indicated, and the use is non-commercial. See: http://creativecommons.org/licenses/by-nc/4.0/.

\section{ORCID iDs}

Mikkel Jon Henningsen http://orcid.org/0000-0002-4331-6094

Christian Beltoft Brøchner http://orcid.org/0000-0001-6838-6729

\section{REFERENCES}

1 Huang C, Wang Y, Li X, et al. Clinical features of patients infected with 2019 novel coronavirus in Wuhan, China. The Lancet 2020;395:497-506.

2 Ksiazek TG, Erdman D, Goldsmith CS, et al. A novel coronavirus associated with severe acute respiratory syndrome. N Engl J Med Overseas Ed 2003;348:1953-66.

3 de Groot RJ, Baker SC, Baric RS, et al. Middle East respiratory syndrome coronavirus (MERS-CoV): announcement of the coronavirus study group. J Virol 2013;87:7790-2.

4 Tang $X$, Wu C, Li X, et al. On the origin and continuing evolution of SARS-CoV-2. Natl Sci Rev 2020;7:1012-23.

5 Letko M, Marzi A, Munster V. Functional assessment of cell entry and receptor usage for SARS-CoV-2 and other lineage $B$ betacoronaviruses. Nat Microbiol 2020;5:562-9.

6 Khatam-Lashgari A, Henningsen MJ, Olsen KB, et al. Autopsies in pandemics - a perspective on barriers and benefits. Is it time for a revival? APMIS 2021;129:324-39.

7 Hamming I, Timens W, Bulthuis MLC, et al. Tissue distribution of ACE2 protein, the functional receptor for SARS coronavirus. A first step in understanding SARS pathogenesis. J Pathol 2004;203:631-7.

8 de Groot RJ, Baker SC, Baric RS, et al. Middle East respiratory syndrome coronavirus (MERS-CoV): announcement of the coronavirus study group. J Virol 2013;87:7790-2.

9 Menter T, Haslbauer JD, Nienhold R, et al. Postmortem examination of COVID-19 patients reveals diffuse alveolar damage with severe capillary congestion and variegated findings in lungs and other organs suggesting vascular dysfunction. Histopathology 2020;77:198-209.
10 Edler C, Schröder AS, Aepfelbacher M, et al. Dying with SARSCoV-2 infection-an autopsy study of the first consecutive 80 cases in Hamburg, Germany. Int J Legal Med 2020;134:1275-84.

11 Bryce C, Grimes Z, Pujadas E. Pathophysiology of SARS-CoV-2: the Mount Sinai COVID-19 autopsy experience. Mod Pathol 2021:1-12 (published Online First: 2021/04/03).

12 Carsana L, Sonzogni A, Nasr A, et al. Pulmonary post-mortem findings in a series of COVID-19 cases from northern Italy: a twocentre descriptive study. Lancet Infect Dis 2020;20:1135-40.

13 Wichmann D, Sperhake JP, Lutgehetmann M. Autopsy findings and venous thromboembolism in patients with COVID-19. Ann Intern Med 2020.

14 Suess C, Hausmann R. Gross and histopathological pulmonary findings in a COVID-19 associated death during self-isolation. Int J Legal Med 2020;134:1285-90.

15 Tombolini A, Scendoni R. SARS-CoV-2-related deaths in routine forensic autopsy practice: histopathological patterns. Int J Legal Med 2020;134:2205-8.

16 Youd E, Moore L. COVID-19 autopsy in people who died in community settings: the first series. J Clin Pathol 2020;73:840-4.

17 Aguiar D, Lobrinus JA, Schibler M, et al. Inside the lungs of COVID-19 disease. Int J Legal Med 2020;134:1271-4.

18 Høy Marbjerg L, Jacobsen C, Fonager J, et al. Possible involvement of central nervous system in COVID-19 and sequence variability of SARS-CoV-2 revealed in autopsy tissue samples: a case report. Clin Pathol 2021;14:2632010X2110060.

19 Romanova ES, Vasilyev W, Startseva G, et al. Cause of death based on systematic post-mortem studies in patients with positive SARSCoV-2 tissue PCR during the COVID-19 pandemic. J Intern Med 2021. doi:10.1111/joim.13300. [Epub ahead of print: 19 Apr 2021].

20 Zhou $\mathrm{P}$, Yang X-L, Wang X-G, et al. A pneumonia outbreak associated with a new coronavirus of probable bat origin. Nature 2020;579:270-3.

21 Liu Z, Xiao X, Wei X. Composition and divergence of coronavirus spike proteins and host ACE2 receptors predict potential intermediate hosts of SARS-CoV-2. J Med Virol 2020;92:595-601.

22 Oudit GY, Kassiri Z, Jiang C, et al. Sars-Coronavirus modulation of myocardial ACE2 expression and inflammation in patients with SARS. Eur J Clin Invest 2009;39:618-25.

23 Nägele MP, Haubner B, Tanner FC, et al. Endothelial dysfunction in COVID-19: current findings and therapeutic implications. Atherosclerosis 2020;314:58-62.

24 Zou X, Chen K, Zou J, et al. Single-cell RNA-seq data analysis on the receptor ACE2 expression reveals the potential risk of different human organs vulnerable to $2019-\mathrm{nCoV}$ infection. Front Med 2020;14:185-92.

25 Siddiqi HK, Mehra MR. COVID-19 illness in native and immunosuppressed states: a clinical-therapeutic staging proposal. $J$ Heart Lung Transplant 2020;39:405-7.

26 Chen N, Zhou M, Dong X, et al. Epidemiological and clinical characteristics of 99 cases of 2019 novel coronavirus pneumonia in Wuhan, China: a descriptive study. Lancet 2020;395:507-13.

27 Wang D, Hu B, Hu C, et al. Clinical characteristics of 138 hospitalized patients with 2019 novel coronavirus-infected pneumonia in Wuhan, China. JAMA 2020;323:1061-9.

28 Fried MW, Crawford JM, Mospan AR, et al. Patient characteristics and outcomes of 11721 patients with coronavirus disease 2019 (COVID-19) hospitalized across the United States. Clin Infect Dis 2021;72:e558-65.

29 Clerkin KJ, Fried JA, Raikhelkar J. Coronavirus disease 2019 (COVID-19) and cardiovascular disease. Circulation.

30 Yang JZY, Gou X, Pu K. Prevalence of comorbidities in the novel Wuhan coronavirus (COVID-19) infection: a systematic review and meta-analysis. International Journal of Infectious Diseases 2020.

31 Zheng Y-Y, Ma Y-T, Zhang J-Y. COVID-19 and the cardiovascular system. Nat Rev Cardiol 2020;17:259-60.

32 Tavazzi G, Pellegrini C, Maurelli M, et al. Myocardial localization of coronavirus in COVID-19 cardiogenic shock. Eur J Heart Fail 2020;22:911-5.

$33 \mathrm{Ma} \mathrm{C}, \mathrm{Gu}$ J, Hou P. Incidence, clinical characteristics and prognostic factor of patients with COVID-19: a systematic review and meta-analysis. medRxiv 2020.

34 Zhou F, Yu T, Du R, et al. Clinical course and risk factors for mortality of adult inpatients with COVID-19 in Wuhan, China: a retrospective cohort study. Lancet 2020;395:1054-62.

35 Basso C, Leone O, Rizzo S, et al. Pathological features of COVID19-associated myocardial injury: a multicentre cardiovascular pathology study. Eur Heart J 2020;41:3827-35.

36 Wong CK, Lam CWK, Wu AKL, et al. Plasma inflammatory cytokines and chemokines in severe acute respiratory syndrome. Clin Exp Immunol 2004:136:95-103. 
37 Mahallawi WH, Khabour OF, Zhang Q, et al. Mers-cov infection in humans is associated with a pro-inflammatory Th1 and Th17 cytokine profile. Cytokine 2018;104:8-13.

$38 \mathrm{Xu}$ Z, Shi L, Wang Y, et al. Pathological findings of COVID-19 associated with acute respiratory distress syndrome. Lancet Respir Med 2020;8:420-2.

39 Cameron MJ, Bermejo-Martin JF, Danesh A, et al. Human immunopathogenesis of severe acute respiratory syndrome (SARS). Virus Res 2008:133:13-19.

40 Cameron MJ, Ran L, Xu L, et al. Interferon-mediated immunopathological events are associated with atypical innate and adaptive immune responses in patients with severe acute respiratory syndrome. J Virol 2007;81:8692-706.

41 Nalbandian A, Sehgal K, Gupta A, et al. Post-acute COVID-19 syndrome. Nat Med 2021;27:601-15.

42 Ayoubkhani D, Khunti K, Nafilyan V, et al. Post-covid syndrome in individuals admitted to hospital with covid-19: retrospective cohort study. BMJ 2021;372:n693.

43 Al-Aly Z, Xie Y, Bowe B. High-Dimensional characterization of postacute sequelae of COVID-19. Nature 2021:594:259-64.

44 Yan L, Mir M, Sanchez P, et al. COVID-19 in a Hispanic woman. Arch Pathol Lab Med 2020;144:1041-7.

45 Adachi T, Chong J-M, Nakajima N, et al. Clinicopathologic and immunohistochemical findings from autopsy of patient with COVID-19, Japan. Emerg Infect Dis 2020;26:2157-61.

46 Falasca L, Nardacci R, Colombo D, et al. Postmortem findings in Italian patients with COVID-19: a descriptive full autopsy study of cases with and without comorbidities. $J$ Infect Dis 2020;222:1807-15.

47 Prilutskiy A, Kritselis M, Shevtsov A, et al. SARS-CoV-2 infectionassociated hemophagocytic lymphohistiocytosis. Am J Clin Pathol 2020;154:466-74

48 Borczuk AC, Salvatore SP, Seshan SV, et al. COVID-19 pulmonary pathology: a multi-institutional autopsy cohort from Italy and New York city. Mod Pathol 2020;33:2156-68.

49 Remmelink M, De Mendonça R, D'Haene N, et al. Unspecific post-mortem findings despite multiorgan viral spread in COVID-19 patients. Crit Care 2020;24:495.

50 Lax SF, Skok K, Zechner P, et al. Pulmonary arterial thrombosis in COVID-19 with fatal outcome: results from a prospective, single-center, clinicopathologic case series. Ann Intern Med 2020;173:350-61.

51 Elsoukkary SS, Mostyka M, Dillard A, et al. Autopsy findings in 32 patients with COVID-19: a single-institution experience. Pathobiology 2021;88:56-68.

52 Navarro Conde P, Alemany Monraval P, Medina Medina C, et al. Autopsy findings from the first known death from severe acute respiratory syndrome SARS-CoV-2 in Spain. Rev Esp Patol 2020;53:188-92.

53 NavarroCondePea, COVID-19 Autopsy. Electronic address: anapat. hrc@salud.madrid.org. The first COVID-19 autopsy in Spain performed during the early stages of the pandemic. Rev Esp Patol 2020:53:182-7.

54 Barton LM, Duval EJ, Stroberg E, et al. COVID-19 autopsies, Oklahoma, USA. Am J Clin Pathol 2020;153:725-33.

55 Grimes Z, Bryce C, Sordillo EM, et al. Fatal pulmonary thromboembolism in SARS-CoV-2-infection. Cardiovasc Pathol 2020:48:107227.

56 Varga Z, Flammer AJ, Steiger P, et al. Endothelial cell infection and endotheliitis in COVID-19. Lancet 2020;395:1417-8.

57 Lacy JM, Brooks EG, Akers J, et al. COVID-19: postmortem diagnostic and biosafety considerations. Am J Forensic Med Pathol 2020;41:143-51.

58 Konopka KE, Wilson A, Myers JL. Postmortem lung findings in a patient with asthma and coronavirus disease 2019. Chest 2020;158:e99-101.

59 Fitzek A, Sperhake J, Edler C, et al. Evidence for systematic autopsies in COVID-19 positive deceased: case report of the first German investigated COVID-19 death. Rechtsmedizin 2020:1-6.

60 Craver R, Huber S, Sandomirsky M, et al. Fatal eosinophilic myocarditis in a healthy 17 -year-old male with severe acute respiratory syndrome coronavirus 2 (SARS-CoV-2c). Fetal Pediatr Pathol 2020;39:263-8.

61 Farkash EA, Wilson AM, Jentzen JM. Ultrastructural evidence for direct renal infection with SARS-CoV-2. J Am Soc Nephrol 2020;31:1683-7.

62 Paniz-Mondolfi A, Bryce C, Grimes Z, et al. Central nervous system involvement by severe acute respiratory syndrome coronavirus-2 (SARS-CoV-2). J Med Virol 2020;92:699-702.
63 Zhang H, Zhou P, Wei Y, et al. Histopathologic changes and SARSCoV-2 immunostaining in the lung of a patient with COVID-19. Ann Intern Med 2020;172:629-32.

64 Li G, Fox SE, Summa B. Multiscale 3-dimensional pathology findings of COVID-19 diseased lung using high-resolution cleared tissue microscopy. bioRxiv 2020.

65 Flikweert AW, Grootenboers MJJH, Yick DCY, et al. Late histopathologic characteristics of critically ill COVID-19 patients: different phenotypes without evidence of invasive aspergillosis, a case series. J Crit Care 2020:59:149-55.

66 Dolhnikoff M, Duarte-Neto AN, de Almeida Monteiro RA, et al. Pathological evidence of pulmonary thrombotic phenomena in severe COVID-19. J Thromb Haemost 2020;18:1517-9.

67 Yao XH, Li TY, He ZC, et al. [A pathological report of three COVID-19 cases by minimal invasive autopsies]. Zhonghua Bing Li Xue Za Zhi 2020;49:411-7.

68 Tian S, Xiong Y, Liu H, et al. Pathological study of the 2019 novel coronavirus disease (COVID-19) through postmortem core biopsies. Mod Pathol 2020;33:1007-14.

69 Duarte-Neto AN, Monteiro RAA, da Silva LFF, et al. Pulmonary and systemic involvement in COVID-19 patients assessed with ultrasound-guided minimally invasive autopsy. Histopathology 2020;77:186-97.

70 Bradley BT, Maioli $\mathrm{H}$, Johnston R, et al. Histopathology and ultrastructural findings of fatal COVID-19 infections in Washington state: a case series. Lancet 2020;396:320-32.

71 Ackermann M, Verleden SE, Kuehnel M, et al. Pulmonary vascular Endothelialitis, thrombosis, and angiogenesis in Covid-19. N Engl J Med 2020;383:120-8.

72 Copin M-C, Parmentier E, Duburcq T, et al. Time to consider histologic pattern of lung injury to treat critically ill patients with COVID-19 infection. Intensive Care Med 2020;46:1124-6.

73 Su H, Yang M, Wan C, et al. Renal histopathological analysis of 26 postmortem findings of patients with COVID-19 in China. Kidney Int 2020;98:219-27.

74 Magro C, Mulvey JJ, Berlin D, et al. Complement associated microvascular injury and thrombosis in the pathogenesis of severe COVID-19 infection: a report of five cases. Trans/ Res 2020;220:1-13

75 Li Y, Wu J, Wang S, et al. Progression to fibrosing diffuse alveolar damage in a series of 30 minimally invasive autopsies with COVID-19 pneumonia in Wuhan, China. Histopathology 2021;78:542-55.

76 Sonzogni A, Previtali G, Seghezzi M, et al. Liver histopathology in severe COVID 19 respiratory failure is suggestive of vascular alterations. Liver Int 2020;40:2110-6.

77 Prieto-Pérez L, Fortes J, Soto C, et al. Histiocytic hyperplasia with hemophagocytosis and acute alveolar damage in COVID-19 infection. Mod Pathol 2020;33:2139-46.

78 Schaller T, Hirschbühl K, Burkhardt K, et al. Postmortem examination of patients with COVID-19. JAMA 2020;323:2518-20

79 Fox SE, Akmatbekov A, Harbert JL, et al. Pulmonary and cardiac pathology in African American patients with COVID-19: an autopsy series from new Orleans. Lancet Respir Med 2020;8:681-6.

80 Puelles VG, Lütgehetmann M, Lindenmeyer MT, et al. Multiorgan and renal tropism of SARS-CoV-2. N Engl J Med 2020;383:590-2.

81 De Michele S, Sun Y, Yilmaz MM, et al. Forty postmortem examinations in COVID-19 patients. Am J Clin Pathol 2020;154:748-60.

82 Schurink B, Roos E, Radonic T, et al. Viral presence and immunopathology in patients with lethal COVID-19: a prospective autopsy cohort study. Lancet Microbe 2020;1:e290-9.

83 Hanley B, Naresh KN, Roufosse C, et al. Histopathological findings and viral tropism in UK patients with severe fatal COVID-19: a postmortem study. Lancet Microbe 2020;1:e245-53.

84 Buja LM, Wolf DA, Zhao B, et al. The emerging spectrum of cardiopulmonary pathology of the coronavirus disease 2019 (COVID-19): report of 3 autopsies from Houston, Texas, and review of autopsy findings from other United States cities. Cardiovasc Pathol 2020;48:107233.

85 Rapkiewicz AV, Mai X, Carsons SE, et al. Megakaryocytes and platelet-fibrin thrombi characterize multi-organ thrombosis at autopsy in COVID-19: a case series. EClinicalMedicine 2020;24:100434.

86 Attoh S, Segborwotso RP, Akoriyea SK, et al. COVID-19 autopsy reports from the Ga-East municipal and the 37 military hospitals in Accra, Ghana. Ghana Med J 2020;54:52-61.

87 Malézieux-Picard A, Ferrer Soler C, De Macedo Ferreira D, et al. Undetected causes of death in hospitalized elderly with COVID-19: lessons from autopsy. J Clin Med 2021;10. doi:10.3390/ jcm10071337. [Epub ahead of print: 2403 2021]. 
88 Evert K, Dienemann T, Brochhausen C. Autopsy findings after long-term treatment of COVID-19 patients with microbiological correlation. Virchows Arch 2021:1-12 (published Online First: 2021/01/21).

89 Pérez-Mies B, Gómez-Rojo M, Carretero-Barrio I, et al. Pulmonary vascular proliferation in patients with severe COVID-19: an autopsy study. Thorax 2021. doi:10.1136/thoraxinl-2020-216714. [Epub ahead of print: 23 Mar 2021] (published Online First: 2021/03/25).

90 Núñez-Torrón C, Ferrer-Gómez A, Moreno Moreno E, et al. Secondary haemophagocytic lymphohistiocytosis in COVID-19: correlation of the autopsy findings of bone marrow haemophagocytosis with HScore. J Clin Pathol 2021. doi:10.1136/ jclinpath-2020-207337. [Epub ahead of print: 15 Mar 2021] (published Online First: 2021/03/17).

91 Hanley B, Lucas SB, Youd E, et al. Autopsy in suspected COVID-19 cases. J Clin Pathol 2020;73:239-42.

92 Santurro A, Scopetti M, D'Errico S, et al. A technical report from the Italian SARS-CoV-2 outbreak. postmortem sampling and autopsy investigation in cases of suspected or probable COVID-19. Forensic Sci Med Pathol 2020;16:471-6.

93 Sapino A, Facchetti F, Bonoldi E, et al. The autopsy debate during the COVID-19 emergency: the Italian experience. Virchows Arch 2020;476:821-3.

94 Thali MJ, Yen K, Schweitzer W, et al. Virtopsy, a new imaging horizon in forensic pathology: virtual autopsy by postmortem multislice computed tomography (MSCT) and magnetic resonance imaging (MRI)--a feasibility study. J Forensic Sci 2003;48:386-403.

95 Maiese A, Manetti AC, La Russa R, et al. Autopsy findings in COVID-19-related deaths: a literature review. Forensic Sci Med Pathol 2021;17:279-96.

96 Sundhedsdatastyrelsen. Lægemiddelstatistikregisteret. Available: https://www.esundhed.dk/Dokumentation/DocumentationExt ended?id=14 [Accessed 13 Sep 2016].

97 Sundhedsdatastyrelsen. Landspatientregisteret. Available: https:// www.esundhed.dk/Dokumentation/DocumentationExtended?id=5 [Accessed 18 Nov 2016].

98 Denmark S. Highest education attained. Available: https://www.dst $\mathrm{dk} / \mathrm{en} /$ Statistik/dokumentation/documentationofstatistics/highesteducation-attained [Accessed 08 Aug 2020].

99 Importance of postmortem MRI of the brain for forensic practice. 10 Th annual Congress of the International Society of forensic radiology and imaging. Krakow, Poland, 2021.
100 Femia G, Langlois N, Raleigh J, et al. Comparison of conventional autopsy with post-mortem magnetic resonance, computed tomography in determining the cause of unexplained death. Forensic Sci Med Pathol 2021;17:10-18.

101 Knight B. The coroner's autopsy: a guide to non-criminal autopsies for the general pathologist. Churchill Livingstone, 1983.

102 Saphir O. Autopsy diagnosis and technic. P.B. Hoeber, 1958

103 Egger C, Vaucher P, Doenz F, et al. Development and validation of a postmortem radiological alteration index: the RA-index. Int $J$ Legal Med 2012;126:559-66.

104 Cartocci G, Santurro A, Neri M, et al. Post-mortem computed tomography (PMCT) radiological findings and assessment in advanced decomposed bodies. Radiol Med 2019;124:1018-27.

105 Banner J, Høyer CB, Christensen MR, et al. Survive: let the dead help the living - an autopsy-based cohort study for mapping risk markers of death among those with severe mental illnesses. Scandinavian J Forensic Sci 2018;24:7-17.

106 Satturwar S, Fowkes M, Farver C, et al. Postmortem findings associated with SARS-CoV-2: systematic review and meta-analysis. Am J Surg Pathol 2021;45:587-603.

107 Peiris S, Mesa H, Aysola A, et al. Pathological findings in organs and tissues of patients with COVID-19: a systematic review. PLoS One 2021;16:e0250708.

108 Borczuk AC. Pulmonary pathology of COVID-19: a review of autopsy studies. Curr Opin Pulm Med 2021;27:184-92.

109 Matschke J, Lütgehetmann M, Hagel C, et al. Neuropathology of patients with COVID-19 in Germany: a post-mortem case series. Lancet Neurol 2020;19:919-29.

110 Zhao W, Zhong Z, Xie X, et al. Relation between chest CT findings and clinical conditions of coronavirus disease (COVID-19) pneumonia: a multicenter study. AJR Am J Roentgeno 2020;214:1072-7.

111 Xie X, Zhong Z, Zhao W. Chest CT for typical 2019-nCoV pneumonia: relationship to negative RT-PCR testing. Radiology:200343.

112 Christe A, Flach P, Ross S, et al. Clinical radiology and postmortem imaging (Virtopsy) are not the same: specific and unspecific postmortem signs. Leg Med 2010;12:215-22.

113 Høiby N. Pandemics: past, present, future: that is like choosing between cholera and plague. Apmis 2020. 